\title{
PHYTOCHEMICAL SCREENING AND QUANTITATIVE ESTIMATION OF TOTAL PHENOLIC CONTENT AND TOTAL FLAVONOID CONTENT OF GRAINS OF PASPALUM SCROBICULATUM
}

\author{
SHARMA $S^{1 *}$, SAXENA J ${ }^{2}$ \\ ${ }^{1}$ Department Chemistry, Sarojini Naidu Government Girls PG (Auto) College, Shivaji Nagar, Bhopal, Madhya Pradesh, India. ${ }^{2}$ Department \\ Chemistry, Institute for Excellence in Higher Education, Kaliyasot Dam, Kolar Road, Bhopal, Madhya Pradesh, India. \\ Email: swati9488@gmail.com \\ Received: 18 June 2016, Revised and Accepted: 29 June 2016
}

\section{ABSTRACT}

Objective: Paspalum scrobiculatum, commonly known as "Kodo" is a millet variety found in India having medicinal and pharmaceutical importance. Crude extracts of chloroform, ethyl acetate, ethanol, and methanol were evaluated for the presence of total phenolic content (TPC) and total flavonoid content (TFC) of the millet grains.

Method: Phytochemical screening was done for the qualitative basis of the study using standard tests. The TPC was determined by Folin-ciocalteu method with gallic acid as standard at $765 \mathrm{~nm}$ in ultraviolet spectrophotometer. Results were expressed as "mg gallic acid equivalent (GAE)/g extract". The TFC was measured at $510 \mathrm{~nm}$ using rutin as reference standard. Results were expressed as "mg rutin equivalent (RE)/g extract".

Result: Phytochemical tests showed the presence of phenolics and flavonoids in more polar solvent extracts, methanol, and ethanol. Carbohydrates and fats and oils were present in all four extracts. TPC of ethanol extract, $175.94 \pm 1.018$ mg GAE/g extract was found highest. Major flavonoid containing extract was ethanol having TFC $116.48 \pm 1.57 \mathrm{mg} \mathrm{RE} / \mathrm{g}$ extract.

Conclusion: Kodo millet is known for its antidiabetic property, wound healing capacity, and several phenolic and flavonoids have been identified. The presence of good amount of phenolics and flavonoids ascertained by tests indicate the presence of phytochemicals in kodo millet which are having good antioxidant potential is responsible for the bioactivity of these crude extracts. The study on kodo millet can further be done to ascertain its efficacy against target diseases.

Keywords: Paspalum scrobiculatum, Phytochemical, Total phenolic content, Total flavonoid content, Ethanol.

(C) 2016 The Authors. Published by Innovare Academic Sciences Pvt Ltd. This is an open access article under the CC BY license (http://creativecommons. org/licenses/by/4. 0/) DOI: http://dx.doi.org/10.22159/ajpcr.2016.v9i6.13552

\section{INTRODUCTION}

Free radicals are present in the environment as well as in our body as the product of metabolic activities occurring inside us [1,2]. Free radicals are highly unstable species. The chain initiation, propagation, and termination steps are part of a free radical's life cycle. When this cycle disrupts, due to various environmental stress conditions such as industrial pollution, X-ray exposure, and chemicals, a state of oxidative stress occurs [3-5]. Oxidative stress is a situation when steady-state reactive oxygen species (ROS) concentration is transiently or chronically enhanced, disturbing cellular metabolism and its regulation and damaging cellular constituents [6]. ROS influence many physiological processes including host defense and cellular signaling, and their increased production through oxidative stress plays a role in such pathologies as hypertension, atherosclerosis, diabetes, cancer, neurological disorders, and kidney disease [7]. The role of phytochemicals in the treatment of these disorders has gained significant interest in recent years. Antioxidant phytochemicals are present in almost all fruits, vegetables, and medicinal plants and play an important role in the prevention and treatment of chronic diseases instigated by oxidative stress [8]. Thousands of phytochemicals have been identified so far, yet there are a lot more to be studied. Phytochemicals are basically present in plants for protecting them against diseases. When consumed by humans, they protect us as well [9]. Polyphenols and carotenoids are the two main types of antioxidant phytochemicals, which contribute the most to the antioxidant properties [10]. Natural polyphenols are the most abundant antioxidants in human diets, and their radical scavenging activities are well known [11]. Dietary polyphenols could be classified into five classes: Flavonoids, phenolic acids, stilbenes, tannins, and coumarins. Flavonoids can be further categorized as flavonols, flavones, flavanols, flavanones, anthocyanidins, and isoflavonoids [12,13]. Total phenolic content (TPC) and total antioxidant activity in phytochemical extracts may have a direct relationship. When higher TPCs are present, they possess a stronger antioxidant activity [8].

Whole grains such as wheat, barley, maize, rice, and millets have been studied for the presence of polyphenols and their antioxidant activity. Epidemiological studies have shown that consumption of whole grains and grain-based products is associated with reduced risk of chronic diseases [14]. Since they are a part of our daily diet, getting the benefit of antioxidants from these grains is the easiest and most convenient. Millets come fifth in world grain production at 27.82 million metric ton after corn, rice, wheat, and barley; [15] of which, 11.5 million metric ton is produced in India [16]. Various phytochemicals have been reported in all the varieties of millets such as flavonone, tannins, and flavonoid [17] The phytochemical constituents reported in pearl millet were tannins, steroids, phenols, alkaloids, terpenoids, cardiac glycosides, and balsams [18]. Paspalum scrobiculatum, commonly called as kodo millet is found to have good phenolic and flavonoid content [19]. It was found to be higher when compared to other millet and wheat [20].

The present study was conducted on five crude extracts of kodo millet grains based on increasing the polarity of solvents using maceration technique. To evaluate their phenolic and flavonoid content and to make a base for further study of their radical scavenging capacity, a most suitable solvent for maximum phenolic and flavonoid content is determined in this study. 


\section{METHODS}

\section{Chemical reagents}

The chemicals used for the antioxidant assays were methanol, ethanol, petroleum ether, ethyl acetate, chloroform, gallic acid, Folinciocalteu reagent (1:10 in deionized water), $\mathrm{Na}_{2} \mathrm{CO}_{3}(7.5 \% \mathrm{w} / \mathrm{v}$ ), Rutin/ Quercetin, 5\% $\mathrm{NaNO}_{2}, 10 \% \mathrm{AlCl}_{3}, 4 \% \mathrm{NaOH}, \mathrm{HCl}, \mathrm{CH}_{3} \mathrm{COOH}, \mathrm{Pb}(\mathrm{ac})_{2}$ $\mathrm{FeCl}_{3}$, Concentrated $\mathrm{H}_{2} \mathrm{SO}_{4}$, etc. All the reagents used were of analytical grade.

\section{Collection and preparation of plant material}

The grains of kodo millet were collected from local market of Ghughri village of Mandla district, Madhya Pradesh. They were washed, shade dried, grinded, and kept in different solvents (plant material-solvent ratio 1:5) successively using maceration technique based on increasing polarity for 3-7 days with occasional stirring/shaking [21]. The solvent extracts were evaporated to dryness and refrigerated for further experimentation. Pet ether was used for defatting of grains.

Preliminary phytochemical screening of the different plants extracts [22]

Qualitative phytochemical testing of crude extracts was done to study the presence of various phytochemical constituents such as carbohydrates, tannins, phenolic acids, flavonoids, and proteins using standard tests.

Quantitative estimation of Total Phenolic Content (TPC) [23,24]

TPC of all the extracts was determined by Folin-ciocalteu method. Gallic acid was used as reference standard. Different concentrations of gallic acid $(10-100 \mu \mathrm{g} / \mathrm{ml})$ were prepared in methanol. Test sample of each extract was prepared in methanol $(100 \mu \mathrm{g} / \mathrm{ml})$ or solvent of near about the same polarity. $0.5 \mathrm{ml}$ of different concentrations of gallic acid/test sample was added with $2 \mathrm{ml}$ of Folin-ciocalteu reagent followed by addition of $4 \mathrm{ml}$ of sodium carbonate solution. The reaction mixture was incubated for 30 minutes at room temperature with intermittent shaking. The absorbance was taken by ultraviolet (UV) spectrophotometer at $765 \mathrm{~nm}$ using methanol as blank. Standard curve of gallic acid was prepared to find the line of regression $(y=m x+c)$. The TPC was obtained from the calibration curve of gallic acid and expressed as mg gallic acid equivalent (GAE)/g extract or $\mu \mathrm{g} \mathrm{GAE} / \mathrm{mg}$ extract.
Total Flavonoid Content (TFC) [25]

Estimation of TFC was done using colorimetric assay. Rutin was used as reference standard. Different concentrations of rutin $(10-100 \mu \mathrm{g} / \mathrm{ml})$ were prepared in methanol. Test sample of each extract was prepared in methanol $(100 \mu \mathrm{g} / \mathrm{ml})$ or solvent of near about the same polarity. $0.5 \mathrm{ml}$ of the diluted sample solution was mixed with $2 \mathrm{ml}$ of distilled water followed by $0.15 \mathrm{ml}$ of $\mathrm{NaNO}_{2}$ solution. After 6 minutes, $0.15 \mathrm{ml}$ $\mathrm{AlCl}_{3}$ solution was added and allowed to stand for 6 minutes. After that, $2 \mathrm{ml}$ of $\mathrm{NaOH}$ solution was added to the reaction mixture and allowed to stand for 15 minutes. The absorbance was measured at $510 \mathrm{~nm}$ using water as blank by the UV spectrophotometer. The absorbance of test samples was measured by line of regression of standard curve of rutin. TFC was expressed as mg rutin equivalent (RE)/g extract or $\mu \mathrm{g} R E / m g$ extract.

\section{Statistical analysis}

All data were reported as mean \pm standard deviation of three replicates. The data were analyzed using one-way variance analysis (one way ANOVA).

\section{RESULTS AND DISCUSSION}

Phytochemical tests of crude extracts of chloroform, ethyl acetate, methanol, and ethanol indicated the presence of flavonoids, phenolic acids, carbohydrates, fats, oils, etc. Tannins and phenolic acids and flavonoids were found in methanol and ethanol extracts, indicating the polar nature of phytoconstituents present. Proteins and amino acids were present in methanol and ethanol extracts. In a previous study on kodo millet, glutelin was found as major storage protein and lysine as most limiting amino acid [26]. Fats and oils were present in all the crude extracts, and the extracts were oily liquids. This suggested the presence of fixed oils in kodo millet grain. When the millet extracts were subjected to filter paper test, permanent staining was observed on the filter paper which confirmed the presence of fixed oils in kodo millet extracts. It was higher in chloroform and ethyl acetate extracts and to an extent in methanol and ethanol extracts. On analysis by Gas chromatography- Mass Spectrometry (GC-MS) in a previous study conducted on acetone extract of kodo millet, the oil was found to contain esters of four major fatty acids, i.e., oleic acid, stearic acid, palmitic acid, and linoleic acid [27].

Table 1: Phytochemical tests of crude extracts of Paspalum scrobiculatum (P. scrobiculatum)

\begin{tabular}{|c|c|c|c|c|c|c|}
\hline Phytochemical constituents & Screening tests [22] & Pet ether & $\mathrm{CHCl}_{3}$ & Etac & МeOH & EtOH \\
\hline \multirow[t]{4}{*}{ Carbohydrates } & Molish test & - & - & - & + & + \\
\hline & Fehling's test & - & - & - & + & + \\
\hline & Benedict's test & - & - & - & + & + \\
\hline & Barfoed's test & - & - & - & - & - \\
\hline \multirow[t]{2}{*}{ Proteins and amino acids } & Biuret's test & - & - & - & + & + \\
\hline & Ninhydrin test & - & - & - & + & + \\
\hline \multirow[t]{2}{*}{ Glycosides } & Borntrager's test & - & - & - & - & - \\
\hline & Keller - Killiani test & - & - & - & - & - \\
\hline \multirow[t]{4}{*}{ Alkaloids } & Mayer's test & - & - & - & - & - \\
\hline & Dragendroff's test & - & - & - & - & - \\
\hline & Hager's test & - & - & - & - & - \\
\hline & Wagner's test & - & - & - & - & - \\
\hline Saponins & Froth test & - & + & - & + & - \\
\hline \multirow[t]{2}{*}{ Flavonoids } & Lead acetate test & - & - & - & + & + \\
\hline & Alkaline reagent test & - & - & + & + & + \\
\hline Triterpenoids & Libermann - Burchard's test & - & - & - & - & - \\
\hline \multirow[t]{3}{*}{ Tannin and phenolic acids } & Ferric chloride test & - & - & - & + & + \\
\hline & Lead acetate test & - & - & - & + & + \\
\hline & Gelatin test & - & - & - & + & + \\
\hline Fats and oils & Solubility test & + & + & + & + & + \\
\hline \multirow[t]{2}{*}{ Steroids } & Salkowski's test & - & - & - & - & - \\
\hline & Libermann - Burchard's test & - & - & - & - & - \\
\hline
\end{tabular}

(+): Present, (-): Absent. Pet ether: Petroleum ether, $\mathrm{CHCl}_{3}$ : Chloroform, Etac: Ethyl acetate, MeOH: Methanol, EtOH: Ethanol 
Table 2: TPC of $P$. scrobiculatum extracts

\begin{tabular}{ll}
\hline Extract & TPC (mg GAE/g extract) \\
\hline Chloroform & $40.15 \pm 0.17$ \\
Ethyl acetate & $57.70 \pm 0$ \\
Methanol & $113.29 \pm 0.29$ \\
Ethanol & $175.94 \pm 1.018$ \\
\hline
\end{tabular}

' $x$ ' represents quantity/concentration of phenols which is obtained from the equation: $\mathrm{y}=0.0034 \times+0.0028$, where $\mathrm{y}$ is absorbance of samples and $\mathrm{R}^{2}=0.9815$. TPC: Total phenolic content

Table 3: TFC of $P$. scrobiculatum extracts

\begin{tabular}{ll}
\hline Extract & TFC (mg RE/g extract) \\
\hline Chloroform & $4.88 \pm 0.50$ \\
Ethyl acetate & $29.23 \pm 0.25$ \\
Methanol & $103 \pm 1.99$ \\
Ethanol & $116.48 \pm 1.57$ \\
\hline
\end{tabular}

' $\mathrm{x}$ ' represents quantity/concentration of flavonoids which is obtained from the equation: $\mathrm{y}=0.0023 \times+0.0531$, Where $\mathrm{y}=$ absorbance of samples and $\mathrm{R}^{2}=0.9915$. TFC: Total flavonoid content

Table 1 represents various phytochemical tests of crude extracts of P. scrobiculatum

TPC ranged from $40.15 \pm 0.17$ to $175.94 \pm 1.018 \mathrm{mg}$ GAE/g extract, in the order: Chloroform < ethyl acetate $<$ methanol $<$ ethanol. Higher value for phenolic content was observed for more polar methanol and ethanol extracts. Previous studies done on various varieties of millets also reported highest TPC for P. scrobiculatum, compared to finger, foxtail, proso, pearl, and little millets [28]. Phenolic compounds are hydrogen donating in nature, and therefore, prevent us against oxidative stress-related damage. They have antibacterial, antifungal, antiviral, anticancer, and anti-inflammatory properties [29].

TFC was found highest in ethanol extract, $116.48 \pm 1.57 \mathrm{mg} \mathrm{RE} / \mathrm{g}$ extract. It was found negligible in chloroform extract, following the order chloroform $<$ ethyl acetate $<$ methanol $<$ ethanol. TFC was found to be $25.8 \mu \mathrm{mol}$ catechin equivalent/g grain in a study conducted on kodo millet grains using acetone extract [28]. Flavonoids suppress ROS formation by scavenging reactive species [30]. They show antiinflammatory, antiarthritic, and antiallergic activities in vitro, and therefore, may have potential applications in preventing and treating other diseases [31].

A positive correlation [32,33] of 0.92583206 was found for the concentrations of TPC and TFC for the analysis of polyphenol contents of $P$. scrobiculatum. This data suggested that flavonoids are major compounds contributing to total phenolics in P. scrobiculatum extracts. Whole grains are rich in antioxidants, including trace minerals and phenolic compounds, and these compounds have been linked to disease prevention. It has been established that whole-grain intake is protective against cancer, cardiovascular disease, diabetes, and obesity [34].

\section{CONCLUSION}

P. scrobiculatum has been a part of human diet dated back to 3000 years. Its role as antidiabetic, tranquilizing, hypolipidimic, antirheumatic, antifungal, and in the treatment of skin wounds has so far been established. The presence of high amounts of phenolic and flavonoid content in kodo millet suggests the presence of bioactive compounds, which can be potent antioxidants against diseases such as cardiovascular, diabetes, cancer, and age-related diseases and disorders. The present study was conducted on crude extracts of kodo grains using various solvents, in which crude extracts of ethanol showed maximum phenolic and flavonoid content. It has widened the scope of further studies for separation and characterization of crude extracts to separate bioactive components from this millet.

\section{REFERENCES}

1. Rahman K. Studies on free radicals, antioxidants, and co-factors. Clin Interv Aging 2007;2(2):219-36.

2. Lobo V, Patil A, Phatak A, Chandra N. Free radicals, antioxidants and functional foods: Impact on human health. Pharmacogn Rev 2010;4(8):118-26.

3. Gutowski M, Kowalczyk S. A study of free radical chemistry: Their role and pathophysiological significance. Acta Biochim Pol 2013;60(1):1-16.

4. Ashwini AM, Majumdar M. Quantification of phytochemical contents and in vitro antioxidant activity of Exacum Bicolor (Roxb.), An endemic medicinal plant. Int J Pharm Pharm Sci 2015;7(6):225-30.

5. Valko M, Leibfritz D, Moncola J, Cronin MT, Mazur M, Telser J. Free radicals and antioxidants in normal physiological functions and human disease. Int J Biochem Cell Biol 2007;39(1):44-84.

6. Lushchak VI. Classification of oxidative stress based on its intensity. EXCLI J 2014;13:922-37.

7. Paravicini TM, Touyz RM. NADPH oxidases, reactive oxygen species, and hypertension: Clinical implications and therapeutic possibilities. Diabetes Care 2008;31(2):170-80.

8. Zhang YJ, Gan RY, Li S, Zhou Y, Li AN, Xu DP, et al. Antioxidant phytochemicals for the prevention and treatment of chronic diseases. Molecules 2015;20:21138-56.

9. Batta A. A review on phytochemicals and their activities. Int J Curr Res Med Sci 2016;2(1):20-8.

10. Doughari HJ. Phytochemicals: Extraction methods, basic structures and mode of action as potential chemotherapeutic agents. Phytochemicals - A Global Perspective of Their Role in Nutrition and Health. Rijeka, Croatia: InTech; 2012. p. 1-33.

11. Ozcan T, Bayizit AA, Ersan LY, Delikanli B. Phenolics in human health Int J Chem Eng Appl 2014;5(5):393-6.

12. Pandey KB, Rizvi SI. Plant polyphenols as dietary antioxidants in human health and disease. Oxid Med Cell Longev 2009;2(5):270-8.

13. Tsao R. Chemistry and biochemistry of dietary polyphenols. Nutrients 2010;2(12):1231-46.

14. Adom KK, Liu RH. Antioxidant activity of grains. J Agric Food Chem 2002;50(21):6182-7.

15. Available from: http://www.statista.com/statistics/263977/world-grainproduction-by-type/. [Last retrieved on 2016 Jun 06].

16. Available from: http://www.indexmundi.com/ agriculture/?commodity=millet. [Last retrieved on 2016 Jun 06].

17. Purewal SS. Phytochemical analysis of the ethanolic extracts of different pearl millet (Pennisetum glaucum) varieties. J Nat Prod Plant Resour 2014;4(5):19-23.

18. Bwai M, Afolayan M, Odukomaiya D, Abayomi O. Proximate composition, mineral and phytochemical constituents of Eleusine coracana (finger millet). Int J Adv Chem 2014;2(2):171-4.

19. Bhatia G, Joshi S, Barve A, Nema RK, Joshi A, Gehlot S. Phytochemical studies of the grains of Paspalum scrobiculatum. Int J Pharm Clin Res 2010;2(2):66-7.

20. Mishra V, Yadav N, Pandey S, Puranik V. Bioactive components and nutritional evaluation of underutilized cereals. Ann Phytomed 2014;3(2):46-9

21. Sasidharan S, Chen Y, Saravanan D, Sundram KM, Yoga Latha L. Extraction, isolation and characterization of bioactive compounds from plants' extracts. Afr J Tradit Complement Altern Med 2011;8(1):1-10.

22. Kokate CK, Purohit AP, Gokhale SB. Pharmacognosy. Practical Pharmacognosy. $16^{\text {th }}$ ed., Vol. New Delhi: Nirali Publishers; 1993. p. 493-7.

23. Ainsworth EA, Gillespie KM. Estimation of total phenolic content and other oxidation substrates in plant tissues using folin-ciocalteu reagent. Nat Protoc 2007;2(4):875-7.

24. Alhakmani F, Kumar S, Khan SA. Estimation of total phenolic content, in-vitro antioxidant and anti-inflammatory activity of flowers of Moringa oleifera. Asian Pac J Trop Biomed 2013;3(8):623-7.

25. Zhiesen J, Mengcheng T, Jianming W. The determination flavonoid contents in mulberry and their scavenging effects on superoxide radicals. Food Chem 1999;64(4):555-9.

26. Kiran P, Denni M, Daniel M. Antidiabetic principles, phospholipids and fixed oil of kodo millet (Paspalum scrobiculatum Linn.). Indian J Appl Res 2014;4(2):13-5.

27. Sudharshana L, Monteiro P, Ramachandra G. Studies on the proteins of kodo millet (Paspalum scrobiculatum). J Sci Food Agric 1988;42(4):315-23.

28. Chandrasekara A, Shahidi F. Content of insoluble bound phenolics 
in millets and their contribution to antioxidant capacity. J Agric Food Chem 2010;58(11):6706-14.

29. Anokwuru CP, Esiaba I, Ajibaye O, Ayobami O. Polyphenolic conten and antioxidant activity of Hibiscus sabdariffa Calyx. Res J Med Plant 2011;5(5):557-66

30. Babaa SA, Malikb SA. Determination of total phenolic and flavonoid content, antimicrobial and antioxidant activity of a root extract of Arisaema jacquemontii Blume. J Taibah Univ Sci 2015;6(4):449-54.

31. Borkataky M, Kakoty BB, Saikia LR. Influence of total phenolic conten and total flavonoid content on the DPPH radical scavenging activity of
Eclipta alba (L.) Hassk. Int J Pharm Pharm Sci 2013;5(1):324-27.

32. Do QD, Angkawijayaa AE, Tran-Nguyena PL, Huynhb LH, Soetaredjoc FE, Ismadjic S, et al. Effect of extraction solvent on total pheno content, total flavonoid content, and antioxidant activity of Limnophila aromatic. J Food Drug Anal 2014;22(3):296-302.

33. Zhang A, Fang Y, Wang H, Li H, Zhang Z. Free-radical scavenging properties and reducing power of grape cane extracts from 11 selected grape cultivars widely grown in China. Molecules 2011;16:10104-22.

34. Slavin J. Why whole grains are protective: Biological mechanisms. Proc Nutr Soc 2003;62(1):129-34 